\title{
AgROTURISMO: O CASO DA PRODUÇÃO DE ALFAZEMA
}

\author{
Ilda Paixão \\ Pedro Carvalho ${ }^{2}$
}

\begin{abstract}
Resumo: Na atualidade, assiste-se a um cenário de mudanças na estrutura de comportamentos e motivações da população quanto a hábitos de consumo. É neste contexto que se acentua a valorização dos recursos endógenos de territórios de baixa densidade. Também a procura de produtos transformados a partir de plantas, designadamente as aromáticas e medicinais, tem sofrido uma procura crescente. É, portanto, sob este paradigma, que o presente trabalho pretende, por um lado, contextualizar o mercado ao nível das microempresas no âmbito da produção de alfazema no âmbito dos agronegócios e da sua importância para o desenvolvimento local e, por outro, apresentar uma ideia de negócio de uma empresa de agroturismo, a "Alphazema-Quinta Pedagógica".

Para tanto, recorreu-se a diversas opções metodológicas privilegiando-se as análises concetual, legislativa, estatística e de estudos com vista à consolidação de informação e construção de instrumentos que permitam a tomada de decisões, quanto à trajetória que se considera preponderante na implementação de um agronegócio.

O caso da Alphazema - Quinta Pedagógica propõe-se alcançar a diferenciação pela diversificação de serviços e produtos associados ao cultivo da lavanda (vulgo alfazema), optando por atuar em três áreas de negócio distintas mas complementares. A primeira, e o core business, é a produção de lavanda e, a partir desta, outras atividades que daí são subsidiárias, como a produção e transformação de produtos agroalimentares, a comercialização de acessórios com imagem da empresa e, por fim, o desenvolvimento de atividades de Agroturismo.

Resulta como principal reflexão deste trabalho, que as atividades empresariais em territórios rurais dispõem, hoje, de novas oportunidades face à transformação social e à gradual abordagem da
\end{abstract}

1 Diretora do Núcleo de Apoio à Direção do ISS, I.P./Centro Distrital de Castelo Branco. E-mail: ilda.paixao@gmail.com

2 Docente na Escola Superior de Gestão do Instituto Politécnico de Castelo Branco. Email: pcarvalho@ipcb.pt 
economia regional. Todavia, existe a necessidade de uma aposta clara na diversificação e na modernização, que lhes permitam acrescentar valor às potencialidades dos recursos próprios e das envolventes territorial, cultural e patrimonial.

Palavras-chave: Plantas Aromáticas e Medicinais, Lavanda, Produtos tradicionais e artesanais, Turismo em Espaço Rural, Agroturismo

\begin{abstract}
Today, there are several changes on the structure of behaviour and motivations of population related to consumption habits. In this context it emerges a propensity to endogenous resources of low density territories. At the same time the demand for processed products from medicinal and aromatic plants has also increased.. So it is under this paradigm that the present work intends to contextualize the market of micro companies in agribusiness and its importance to local development and also project the creation of a agro tourism company the "Alphazema - Pedagogical Farm".

In order to do that several methodological options were taken such as the conceptual and legislative analyses of content, statistics and studies concerning a better knowledge of information and construction of instruments that allow a better decision when deciding the correct way to implement the agrotourism company.

So, for that reason this dissertation aims the establishment of the agrotourism company, "Alphazema - Pedagogical Farm", a pedagogical farm that offers a huge diversity of services and products associated with the Lavender Angustifólia growing. The main purpose is to strengthen its information in order to make decisions of what really is meant to achieve with the creation of the company. The company also seeks to be known for its quality of diversity present in three main business segments. The first one and core business is the production of organic Lavender. From this activity there are also others that arise such as the production and processing of agro food, distribution of accessories with the company's layout, and the development of agrotourism activities.

From this work it is clear that business activities in rural areas have, nowadays, new opportunities due to social changes and gradual regional economy approach, but there is a need of modernisation and diversification that allow this business to add value to its own resources and potentialities and also to territorial, cultural and patrimonial areas.
\end{abstract}

Keywords: Aromatic and medicinal Plants, Lavender, Traditional Crafts Items, Rural Tourism, Agro tourism 


\section{INTRODUÇÃO}

Nas sociedades modernas ocidentais e num contexto de crescente globalização da informação, da economia de mercados e das consequentes alterações sociais que se vêm verificando, surgem, hoje, novas oportunidades para as empresas, permitindo-lhes operar num mercado com características globais (Mancebo, 2002). Todavia, emergem também novas dificuldades, pois as exigências e as incertezas do mercado só podem ser ultrapassadas com estratégias de competitividade bem articuladas, as quais se tornam cada vez mais necessárias dado o cenário vigente de políticas marcadas por acentuadas restrições, problemas estruturais e constrangimentos macroeconómicos, como sucede no seio da União Europeia.

É neste ambiente de crise e reduzido crescimento que, todos os dias, nos deparamos com medidas que visam contornar as limitações ao tão aspirado crescimento económico sólido e duradouro dos Estados Membros. Em Portugal, esta tarefa tem sido particularmente difícil já que, sendo um dos Estados Membros que passou por um Plano de Ajustamento Económico e Financeiro (PAEF) assente em medidas de caráter muito restritivo (designadamente em termos de aumento da carga fiscal, diminuição da despesa e redução dos salários, como medidas decorrentes do Memorando de Entendimento sobre as Condicionalidades de Política Económica, $\left.(2011)^{3}\right)$, advêm outras condicionantes, atualmente objeto de grandes preocupações, que constituirão, certamente, uma limitação ao crescimento económico que se pretende. Como referido no Boletim Económico do Banco de Portugal, "a incerteza tem sido um aspeto frequentemente referido para explicar a evolução relativamente fraca das economias avançadas no período subsequente à crise financeira de 2008 ". Segundo a mesma fonte, apesar da incerteza não ser o único fator que levou às variações do PIB, o seu impacto foi considerável durante os períodos recessivos relacionados com as crises financeiras e da dívida soberana que se voltou a acentuar no primeiro trimestre de 2016, devido à indefinição do setor bancário europeu e do resultado do referendo no Reino Unido.

À luz deste cenário, assistimos, portanto, a um incipiente crescimento económico interno, que tem um efeito limitador no investimento e no consumo, factos que resultam em desafios diários para as empresas já instaladas e para as que se pretendem instalar. As empresas de mercado

3 Acordo efetuado entre o Governo português e a troika e que estipula as linhas de orientação a seguir em termos políticos e económicos. 
doméstico, em particular, têm pela frente o grande desafio de conseguirem tirar partido das mudanças como processo de transformação e aumentar a competitividade.

Não obstante as contrariedades conjunturais referidas, é numa perspetiva de uma eventual iniciativa empreendedora individual, que o exemplo da criação da empresa Alphazema - Quinta Pedagógica pretende consubstanciar um negócio de Agroturismo que vá ao encontro das novas tendências de consumo e de ocupação de tempos livres, apostando na dinamização de atividades turísticas de animação e lazer em contexto rural e na valorização de produtos agrícolas locais produzidos de forma artesanal.

\section{TURISMO}

A literatura remete-nos para inúmeros conceitos e perspetivas de encarar o turismo. Por exemplo, para De La Torre (1992), o Turismo é um fenómeno social que consiste no deslocamento voluntário e temporário de indivíduos que, fundamentalmente por motivos de recreação, descanso, cultura ou saúde, saem do seu local de residência habitual para outro, no qual não exercem nenhuma atividade lucrativa nem remunerada, gerando múltiplas inter-relações de importância social, económica e cultural.

A WTTC - World Travel \& Tourism Council (2015)4 reforça que o Turismo é essencial para o desenvolvimento económico e social de qualquer país sendo, por um lado, uma fonte geradora de negócios, comércio, investimento de capital, criação de emprego e empreendedorismo e, por outro, um aliado na proteção dos valores culturais e patrimoniais.

Dos dados apresentados pela WTTC quanto ao impacto do setor, podemos depreender que o turismo é um dos setores que gera maior riqueza e emprego a nível mundial pois o contributo direto deste para o PIB total foi de $6,0 \%$.

Deste modo, infere Santos, (2011), citanto Lipovetsky (2006), que estamos perante "uma sociedade de consumo, herdeira dos mercados em massa e dos consumos em massa", mas que, segundo Santos, se encontra em mudança, designadamente ao nível do consumo turístico, valorizando cada vez mais "o consumo emocional, a participação e a experiência de turismos alternativos, de turismo de nicho. Esta nova relação com os bens, os produtos, os modos (o saber/fazer) e os espaços são também um legado

4 Conselho Mundial de Viagens e Turismo 
de conhecimento que nos leva a pensar com acuidade sobre as relações que estabelecemos com os lugares".

Assim, por força das alterações na estrutura comportamental dos consumidores quanto à preocupação com a saúde e bem-estar, da reforçada exigência ao nível das rotinas pessoais e profissionais da sociedade atual e da consequente significância sociocultural e ideológica do turismo, este assume-se como uma fonte de diversificação numa tentativa de dar resposta aos interesses dos consumidores nas mais variadas vertentes, como as listadas no quadro em baixo, sendo considerada uma área de intervenção estratégica do ponto de vista económico.

\section{Quadro I}

Tipologias de Turismo

\begin{tabular}{ll}
\hline Tipologia de Turismo: & Principais pressupostos: \\
\hline Agroturismo & Contacto genuíno e direto com a natureza \\
Turismo cultural & Conhecimento marcos artísticos ou históricos \\
Turismo de consumo & Excursões organizadas com o objetivo de adquirir \\
& produtos \\
Turismo de formação & Atividades formativas relacionadas com estudos \\
Turismo gastronómico & Degustação da comida tradicional \\
Turismo ecológico & Contacto não invasivo com a natureza \\
Turismo de aventura & Prática de desportos de aventura \\
Turismo religioso & Acontecimentos de carácter religioso \\
Turismo de animação e lazer & Realização de eventos e atividades lúdico-recreativas \\
Turismo espacial & Organização de viagens ao espaço (recente) \\
\hline
\end{tabular}

Fonte: Elaboração própria

\subsection{Turismo em Portugal}

Segundo a AICEP - Agência para o Investimento e Comércio Externo de Portugal, E.P.E., Portugal "tem uma localização privilegiada para aceder a mercados relevantes". A mesma Agência, citando a Organização Mundial de Turismo - OMT (UNWTO World Tourism Barometer January 2017), destaca que em 2015 Portugal foi o $26^{\circ}$ mercado mundial (e $9^{\circ}$ da UE) em termos de receitas de turismo e o $34^{\circ}$ mercado recetor de turistas, tendo sido registadas 10,1 milhões de chegadas.

Os dados do boletim estatístico do Banco de Portugal e do anuário estatístico do INE, referentes a 2015, apontam o setor como a atividade exportadora mais relevante da economia portuguesa com cerca de 11,5 mil milhões de euros e com um peso de $15,6 \%$ do total exportações e de 
45,2\% do total das exportações de Serviços (venda dos serviços para o mercado externo), o que configura mais de $4 \%$ do PIB.

Ainda, segundo dados retirados do INE, podemos referir que em termos de dormidas de estrangeiros, se verificou um crescimento sustentado ao longo dos últimos cinco anos, alcançando cerca de 38,3 milhões $(+11,4 \%$ face lustro anterior). Também ao nível da ocupação hoteleira verificaramse taxas elevadas, passando-se de 42,4\% em 2014 para 46,1\% em 2015.

A crescente procura, aliada à gradual melhoria da qualidade da oferta, resultou nos indicadores favoráveis que se analisaram, os quais, segundo os dados já disponíveis de 2016, mantêm a linha de crescimento e qualidade conseguida em 2015. Esse reconhecimento foi plasmado na gala dos World Travel Awards (2016)5, tendo Portugal vencido 24 das 91 nomeações que tinha a concurso, quando em 2015 tinha sido premiado em 14 categorias (a nível europeu).

Os dados provisórios divulgados pelo INE, relativamente ao ano 2016, apontam para um crescimento de mais " $14 \%$ de turistas e $17 \%$ de receitas" em relação a 2015, apresentando um ritmo de crescimento superior à média da Europa, reiterando, assim, a ideia de que o Turismo é um mercado promissor.

Caracterizado por uma geografia diversificada - planícies, montanhas, praias, ilhas, florestas, vinhas, - um clima apetecível e uma forte componente histórica presente no património disperso pelas vilas e cidades, Portugal é considerado um país com potencial de desenvolvimento turístico, possuidor de elementos diferenciadores da maior parte dos destinos turísticos europeus.

\subsection{Turismo no Centro}

É consensual que o turismo tem um papel cada vez mais importante para a economia das regiões mas, tal como noutras vertentes, também nesta área é incontestável que Portugal é um país de marcadas assimetrias. Ou seja, os principais polos de atração turística continuam a ser o Algarve e Lisboa que, de acordo com dados do INE, no ano de 2015, abarcaram $73,6 \%$ das dormidas totais, detendo, portanto, quase três quartos das dormidas e apresentando as melhores taxas de ocupação e, consequentemente, de proveitos, a saber:

No total de pernoitas, naquele ano, o destino eleito pelos turistas foi o Algarve, com 16347425 dormidas, seguido de Lisboa com 11597 696, a

5 Prémio destinado a reconhecer, recompensar e celebrar a excelência em todos os setores da indústria global de viagens e turismo. 
Madeira com 6125 116, depois o Norte com 5558 794, o Centro com 4 086 584, o Alentejo com 1357 200, e, por último, os Açores, com 1274 207.

A evolução do mercado na zona centro apresenta indicadores positivos, pois conforme publicado no boletim "Turismo em Números" do Turismo do Centro, os proveitos na região Centro aumentaram em 2015 em 14,7\% face ao ano anterior.

Neste ano, o Centro de Portugal ultrapassou a marca dos 4 milhões de dormidas com um aumento de $9,7 \%$ face aos resultados do ano anterior, apresentando um crescimento significativo relativamente no que concerne ao mercado externo $(10,6 \%)$, e um aumento consistente quanto ao mercado interno $(8,8 \%)$.

\subsection{O Turismo no Distrito de Castelo Branco}

As novas tendências, em matéria de turismo, assentam na escolha de destinos alternativos e novos produtos turísticos face à oferta turística massificada. Esta mudança é uma janela de oportunidade para as regiões de baixa densidade populacional, na medida em que lhes permite criar produtos que vão de encontro às necessidades sentidas pelos turistas, pois são possuidoras de recursos endógenos com grandes potencialidades.

Das serras e áreas protegidas, paisagens rurais, património arqueológico e histórico, arte rupestre, feiras e romarias, usos e costumes, músicas e trajes populares, artes e ofícios tradicionais, artesanato agroalimentar, património gastronómico e habitação tradicional, o distrito de Castelo Branco apresenta toda uma conjugação de indiscutíveis vetores de atração turística.

Sabendo que os recursos existem, o desafio está em criar sinergias oferecendo produtos inovadores que não se fechem em si mesmos e que interajam com os núcleos históricos, com as atividades rurais, com as infraestruturas e equipamentos modernos, como vetores de desenvolvimento de segmentos como o Turismo em Espaço Rural, Agroturismo, Ecoturismo, Enoturismo, etc.

\subsection{Turismo em Espaço Rural (TER)}

O TER consiste no conjunto de atividades, serviços de alojamento e animação, em empreendimentos de natureza familiar, realizados e prestados mediante remuneração, em zonas rurais. Do ponto de vista legislativo, em Portugal, o TER, teve o seu início com o Decreto-Lei n²51/84, de 25 de julho, que definia a inserção no mercado turístico de 
quartos particulares, moradias e apartamentos considerados no âmbito do turismo de habitação. É, no entanto, com a entrada de Portugal na Comunidade Europeia, que a evolução deste tipo de Turismo se acentua, devido ao investimento europeu nesta vertente, com o objetivo de fixar populações em zonas consideradas em desequilíbrio económico e populacional. O Decreto-Lei $423 / 83$, de 5 de dezembro ${ }^{6}$, encara o TER como uma forma de "revitalizar e desenvolver o tecido económico rural, contribuindo para o aumento do rendimento das populações locais e criando condições para o aumento da oferta de emprego e fixação das referidas populações", recorrendo, para tal, ao desenvolvimento de atividades complementares que "se destinem à ocupação dos tempos livres dos turistas e contribuam para a divulgação das características, dos recursos e das tradições das regiões, designadamente o seu património natural, paisagístico e cultural, os itinerários temáticos, a gastronomia, o folclore, a caça, a pesca, os jogos e os transportes tradicionais". Esta legislação promovia a dinamização de serviços complementares de TER, através do recurso a atividades de animação, artesanato, cultura, desporto e recreio, permitindo congregar o desenvolvimento de atividades tradicionais em espaços rurais com o alojamento local.

Defende Moreira (2003), que a visão hegemónica do mundo rural, construída na modernidade, encontra-se em processo de "mudança cultural", o que faz "emergir, na nossa contemporaneidade, uma nova visão de rural e de mundo rural". kastenholz (2014) citando Cunha (2009), entende que o desenvolvimento desta vertente turística não teve a ver com a "obediência a uma política regional", mas sim por força de "circunstâncias exógenas ou pela existência de condições naturais que respondiam a motivações da procura turística aproveitadas por interesses exteriores à região e ao país". Este tipo de turismo, para além de ter uma componente diretamente associada à diversificação das atividades agrícolas, interage com um conjunto de outras atividades económicas, como o alojamento, a produção e venda na exploração de produtos artesanais e tradicionais, atividades de animação e lazer, eventos, etc.

6 O Decreto-Lei 251/84 de 25 de julho define o regime de inserção do turismo de habitação na oferta turística portuguesa, nesta fase com especial enfoque no alojamento particular. Através do Decreto-Lei 423/83, de 5 de Dezembro, que prevê expressamente a possibilidade de atribuição de utilidade turística às casas afetas a turismo de habitação, fomenta-se o alargamento do conceito não se esgotando, apenas, na exploração de alojamento turístico, mas sim aliando a oferta de serviços de interesse turístico nos domínios da animação, do artesanato, da cultura e até do desporto e recreio dos turistas. 
Eusébio (2013), refere que as mudanças nos estilos de vida nas sociedades emissoras de turistas remetem para um incremento do interesse pelas áreas rurais, em busca de experiências autênticas e com ênfase nas origens, na cultura, no património material e imaterial, aliadas à crescente preocupação com o meio ambiente. A Direção Geral de Agricultura e Desenvolvimento Regional, no seu site, disponibiliza um conjunto de informação atualizada e caracteriza os consumidores deste tipo de Turismo, como sendo "cultos, com poder económico superior à média, exigentes de qualidade, de genuinidade e em busca das diferença" $e$ identifica os principais fatores chave desta crescente procura:

\section{Quadro II}

Principais fatores-chave da procura de TER
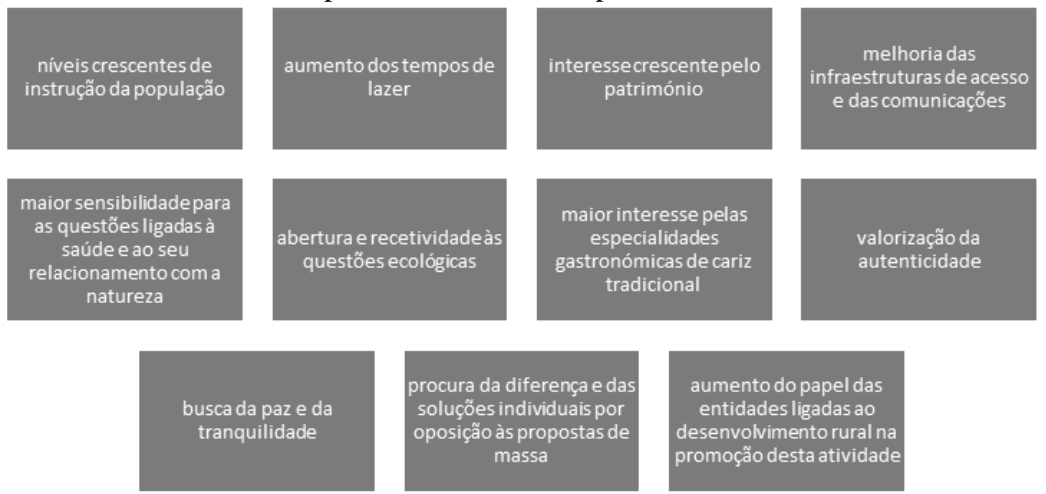

Fonte: Elaboração própria com base em informação da DGADR

Por outro lado, autores como (Vieira, 2010) e (Jesus \& Kastenholz, 2008), entendem o TER como uma possibilidade de reconverter os territórios rurais, seja na sua dimensão económica, social ou demográfica, seja como uma atividade geradora de emprego e de combate ao êxodo das populações rurais.

É neste contexto, e com o intuito de promover o desenvolvimento sustentável de regiões com estas características de interioridade, que as políticas públicas, sejam elas nacionais ou no âmbito da União Europeia, vêm sustentando a necessidade de uma dinâmica apoiada em teorias de "bottom-up" que privilegiam a maximização dos recursos e da cultura local para fins turísticos (Kneafsey, 1998). 


\subsection{Agroturismo}

Refere Miranda (2009), que o Agroturismo pode contribuir significativamente para o desenvolvimento da economia local, gerando receita, emprego e fixando a população em meios com défice populacional. Nesta matéria, os agronegócios são, assim, empreendimentos cada vez mais procurados pelos indivíduos que procuram um turismo diferente. Segundo o Decreto-Lei n. ${ }^{0} 39 / 2008$ de 7 de março ${ }^{7}$, que veio alterar a classificação de TER, passando, então, a integrar oito tipologias de empreendimentos turísticos incorporadas em três áreas: "Casas de campo, Agroturismo e Hotéis rurais", a tipologia de agroturismo deve "permitir aos hóspedes o acompanhamento e conhecimento da atividade agrícola, ou a participação nos trabalhos ai desenvolvidos", podendo englobar, ou não, estrutura de alojamento e o acesso facilitado a outros locais de interesse regional. Nesta perspetiva, acrescenta Partidário (2003), que o desenvolvimento turístico sustentável é consideravelmente importante a três níveis: na melhoria da qualidade de vida da comunidade anfitriã, na garantia de uma experiência de grande qualidade para o visitante e na manutenção da qualidade do ambiente da qual ambos dependem.

Aquele Decreto-Lei, fundamentado pela Portaria n. ${ }^{9} 937 / 2008$ de 20 de agosto, estabelece que os empreendimentos de Agroturismo deverão promover atividades complementares de animação que se destinem exclusivamente à ocupação de tempos livres dos turistas e, ainda, que contribuam para a divulgação das características, produtos e tradições das regiões em que se encontram. A agregação de valor, através da disponibilização de serviços e atividades de animação e lazer, é também uma forma de atração e de despertar a curiosidade dos visitantes.

Desde o início do século XXI tem-se vindo a conferir particular atenção aos agronegócios, os quais têm despertado especial interesse nos proprietários de explorações agrícolas tradicionais, como forma de diversificação das atividades ligadas à exploração com o objetivo de acrescentar valor à produção, respeitando o meio ambiente, a cultura local e permitindo a sustentabilidade.

7 O Decreto-Lei ${ }^{\circ} 39 / 2008$ consagra o novo regime jurídico da instalação, exploração e funcionamento dos empreendimentos turísticos, reunindo num único diploma as disposições comuns a todos os empreendimentos. A Portaria n. $.^{\circ} 937 / 2008$ define empreendimento de turismo rural e os requisitos a observar para a respetiva classificação. 


\section{PLANTAS AROMÁTiCAS E MEDICINAIS (PAM)}

As Plantas Aromáticas e Medicinais representam um infindável número de espécies que têm utilizações diversas, designadamente ao nível das indústrias alimentar, farmacêutica, química e cosmética, podendo ser utilizadas de forma natural, processada, através da extração de substâncias ativas ou de óleos essenciais e ainda, ser utilizadas para infusões, dependendo do resultado que se pretende alcançar (MAM - Ministério da Agricultura e do Mar, 2013).

Segundo o dossier técnico Vida Rural "Plantas aromáticas e medicinais, espontâneas ou cultivadas?", do Instituto Nacional de Investigação Agrária e Veterinária, I. P. (INIAV) ${ }^{8}$ citando Figueiredo et al. (2007), " $a$ Península Ibérica é um dos maiores centros de diversidade de plantas aromáticas e medicinais (PAM) do Mundo, devido à influência continental, mediterrânica e atlântica. Das 3800 espécies identificadas na flora do Continente, Açores e Madeira, cerca de 500 são aromáticas e medicinais". O recurso ao consumo alimentar e utilização terapêutica de plantas remonta às civilizações antigas (Mesquita, 2004) e acompanha toda a história da evolução humana. Inicialmente, o homem primitivo utilizaria e dependia das plantas como garante da sua própria sobrevivência, numa tentativa de suprir necessidades básicas, recorrendo, para tal, a experiências e observação dos efeitos das plantas, conseguindo identificar, desde muito cedo, os "poderes" de cada uma delas: curativas, venenosas, alucinogénias, alimentícias.

Pelo seu odor intenso, estas eram, também, utilizadas em rituais de magia e religiosos já que, em função do seu odor agradável ou desagradável, atraíam a proteção dos deuses e/ou afugentavam os maus espíritos. É também nesta linha de pensamento que Viklund (2010) refere que a necessidade humana de descobrir a cura para as mais variadas doenças se iniciou com a utilização das plantas como os primeiros recursos terapêuticos. A Direção-Geral da Saúde, em documento divulgado em 2013, (Programa Nacional de Alimentação Saudável) refere que "as ervas aromáticas são fornecedoras de proteínas, vitaminas, minerais, fibras, componentes voláteis e substâncias " sendo, portanto, a sua ingestão

8 O Instituto Nacional de Investigação Agrária e Veterinária, I. P. (INIAV) é o laboratório de Estado, da área de competências da Agricultura, Florestas e Desenvolvimento Rural, que desenvolve atividades de investigação nas áreas agronómica e veterinária. 
considerada uma mais-valia do ponto de vista da alimentação, prevenção e cura.

Ao longo do tempo, a utilização das "ervas" foi ganhando outra dimensão e bem cedo começou a ser aproveitada na cosmética, especialmente destiladas para produzir bálsamos, havendo referências descritas em manuscritos antigos datados de 1500 a.C. da sua utilização em embalsamamentos. Mas é na Idade Média, a partir da recolha de saberes antigos e de livros e manuscritos, que os monges se apresentam como os principais estudiosos das propriedades das plantas e sua utilização em alimentos, bebidas e medicamentos, passando, com a evolução dos tempos, a ser objeto de estudo nas universidades, particularmente, de medicina. Difundidas um pouco por todas as culturas civilizacionais, as PAM tiveram grande relevância, por exemplo, nas civilizações orientais onde os resultados terapêuticos destas estiveram na origem da medicina tradicional chinesa. Na cultura egípcia, para além do culto e veneração do divino e da magia com recurso a plantas, estava patente uma forte utilização destas e dos seus óleos essenciais, Cunha et al. (2009). Não obstante, no final do Séc. XIX, aquando da Revolução Industrial, com o desenvolvimento de novos fármacos, cosméticos e alimentos com recurso a produtos químicos, o poder curativo das ervas passou a ser ridicularizado e a sua utilização na culinária e cosmética passou a ser considerada ultrapassada.

Atualmente verifica-se uma inversão desta tendência, assistindo-se a uma cultura de regresso ao natural, ao tradicional e ao biológico. Como resposta a esta procura, multiplicam-se estudos e experiências no sentido de redescobrir os valores alimentares e curativos das plantas e dos seus constituintes a serem utilizados por exemplo em medicamentos de origem vegetal e nas medicinas alternativas.

É nesta dinâmica, que se propicia o aumento de explorações e agronegócios de PAM, especialmente focadas em práticas de cultivo e processamento biológicas e diferenciadas. Trata-se de um setor de atividade que tem apresentado um substancial crescimento, quer do pondo de vista da produção e do número de produtores, quer como objeto de estudo. Um estudo do Gabinete de Planeamento e Políticas do MADRP (2013) revela que as importações quase triplicaram entre 2002 e 2012, a área de explorações passou de 80ha para 180ha no período de 2009 a 2012, com o correspondente aumento de número de produtores, de 93 para 147. É apontado como principal impulsionador o programa PRODER9. O mesmo estudo considera, ainda assim, que Portugal é um pequeno

9 PRODER - Programa de Desenvolvimento Rural 
produtor, na medida em que não faz face às necessidades internas. Estamos perante um setor cujo cultivo está ainda pouco articulado e com grande incidência na recolha de plantas espontâneas, no entanto, tem apresentado taxas de crescimento consideráveis e com boas perspetivas de continuar a desenvolver-se.

A Lavandula, ou Lavanda, é da família das Lamiaceae, assim designada no Código de Nomenclatura Botânica e vulgarmente conhecida em Portugal por Alfazema. Compreende cerca de 200 géneros e 3.500 espécies. São classificadas como ervas perenes, contendo óleos essenciais em todas as partes da planta. É um arbusto de média dimensão (máximo 1 metro de altura). As referências na literatura, adjetivam o seu aroma como relaxante, fresco e limpo, o que nos remete para a origem do nome proveniente do latim "lavare" que significa "lavar". Alguns autores referenciam também a sua origem na palavra latina "livendulo" que significa "lívida ou azulada".

A planta possui propriedades que despertaram a curiosidade ao longo das civilizações em múltiplas utilizações, por exemplo, como planta medicinal, ela vem sendo usada há mais de 2 mil anos. Os árabes, romanos, egípcios e fenícios utilizavam-na, em particular, na mumificação e perfumaria. Na Grécia antiga e na India, era denominada de nardo e, principalmente, utilizada como unguento.

Segundo Souza (2012), vários historiadores defendem que é da autoria de Dioscórides Anazarbeo, importante médico, farmacologista e botânico da Grécia antiga, o primeiro registo escrito sobre a lavanda enquanto erva de cura, datado de meados da década de 60 a.C.. A a lavanda é trazida para a Europa pelos árabes por volta do século VII, e começa a disseminar-se pelo continente. Ganhou importância no combate às infeções, tendo sido bastante empregada durante a Grande Praga de Londres ${ }^{10}$, pois a sua utilização parecia afastar a peste. Com os resultados conseguidos na Primeira Guerra Mundial, no tratamento de ferimentos dos soldados, a lavanda viria a ganhar cada vez mais adeptos e a sua utilização foi sendo diversificada sendo utilizada em "quase tudo", designadamente nas limpezas da casa e da roupa. Mas, tal como na maioria das restantes PAM, a sua utilização e cultura teve uma grande quebra após a revolução industrial e com a inovação de métodos de produção e de produção em escala de produtos substitutos.

10 Epidemia que ocorreu na Inglaterra e que vitimou entre 75.000 a 100.000 pessoas 
Nos dias de hoje, e por força das mudanças de comportamento da sociedade no respeitante à natureza e ao tradicional, a lavanda vem assumindo relevância em diversas áreas. Recentemente, a Universidade de Coimbra (UC) levou a efeito uma investigação intitulada Antifungal activity of phenolic-rich Lavandula multifida L. essential oil, cujos resultados preliminares publicados no European Journal Of Clinical Microbiology \& Infectious Diseases, referem que a planta "tem um bom potencial de vir a ser um futuro fármaco com propriedades antifúngicas". A publicação revela que, para além dos ensaios mostrarem grande potencial da planta para tratar "dermatofitoses", várias micoses da pele, doenças como a "tinha" ou "pé de atleta", podendo ser uma alternativa aos fármacos existentes que revelaram alguns constrangimentos, está em estudo, não só a viabilidade da sua aplicação na industria farmacêutica no que respeita à resistência às doenças em causa, como também se estão a realizar ensaios quanto às suas propriedades anti-inflamatórias.

É neste contexto que têm surgido cada vez mais pesquisadores a aprofundar o estudo da planta e a defender a sua ação antibacteriana e antifúngica, especialmente no respeitante ao óleo extraído da Lavandula angustifólia. Segundo o site do Jardim Botânico da Universidade de Trásos-Montes e Alto Douro, a lavanda é um importante componente na cosmética, especialmente na perfumaria de alta qualidade.

\section{ATIVIDADE PRODUTIVA ARTESANAL}

Se, num passado recente, os produtos tradicionais eram cultivados e desenvolvidos apenas para autossubsistência, o consumidor atual está mais sensibilizado e motivado para a aquisição de produtos resultantes de processos produtivos artesanais, baseados em conhecimentos ancestrais e em técnicas respeitadoras do meio ambiente, da natureza e dos valores nutricionais. O Decreto-Lei $\mathrm{n}^{\circ} 41 / 2001$, de 9 de fevereiro ${ }^{11}$, dá expressão legislativa ao conceito de "atividade artesanal", designando-a como "atividade económica, de reconhecido valor cultural e social, que assenta na produção, restauro ou reparação de bens de valor artístico ou utilitário, de raiz tradicional ou contemporânea, e na prestação de serviços de igual natureza, bem como na produção e confeção tradicionais de bens alimentares".

11 O Decreto-Lei $n^{\circ} 41 / 2001$, de 9 de fevereiro aprova o estatuto do artesão e da unidade produtiva artesanal e define o respetivo processo de acreditação, bem como os requisitos a que devem obedecer os artesãoes e as atividades produtivas artesanais. 
Assim, os produtos tradicionais têm conquistado um considerável número de admiradores e consumidores e estão a ser encarados, pelos agricultores, como uma oportunidade de criação de novos negócios. Apesar de se tratar de produtos, anteriormente considerados, como destinados exclusivamente ao mercado local e regional, os produtores e entidades envolvidas estão cada vez mais focados nas vendas internacionais. Segundo a AICEP, entre 2005 e 2012, as exportações cresceram cerca de $95 \%$ em valor, de 2.470 .795 euros passaram para 4.810.251 euros, e foi no setor agroalimentar que se verificou a maior subida (108\%). É nesta perspetiva que BERNAT (1996) acrescenta que, por si só, a palavra "artesanal" remete para algo feito ou produzido manualmente, mas com outra amplitude, pois para além de estar associada ao "natural", "descontaminado" e "tradicional" pode, igualmente, simbolizar uma forma de estar, oposta à forma de viver urbana e industrial.

As medidas de gestão dos territórios de baixa densidade têm vindo a desenvolver algumas estratégias de desenvolvimento regional assentes numa dinâmica de valorização e recuperação dos produtos, saberes e serviços locais (Silva et al., 2010). Para o efeito, vêm sendo criadas estratégias de marketing territorial, criação de infraestruturas, disponibilização de redes de parcerias e de ligações externas e apoio a estruturas ligadas a I\&D e Tecnologias, com o objetivo de inovar o tradicional e fomentar a implantação e/ou consolidação de unidades produtivas de iniciativa privada.

À semelhança do que acontece noutros setores, as características dos mercados exigem inovação e diferenciação. "No imaginário das populações urbanas atuais, a ruralidade é entendida como uma antítese e negação da cidade, a ruralidade é reportada aos ambientes bucólicos e tranquilos, é vista como um modo de vida saudável e natural, confundida com uma vivência fraterna em pequenas comunidades. Ao presumir que a ruralidade dos tempos passados patenteava todos os valores positivos, o imaginário de hoje passa a defende-la, em virtude da urbanidade" (Pardal, 2002). Com vista a uma política de coesão territorial, no atual Quadro Comunitário de Apoio, Portugal 2020, foram inseridas, nos Programas Operacionais Regionais das Regiões mais desertificadas, algumas medidas vocacionadas para o apoio a estas áreas de baixa densidade populacional, através da criação de estímulos ao investimento e à criação de emprego, com foco na valorização das produções, do ambiente, das condições de vida e das acessibilidades. 
Segundo a reflexão estratégica intitulada "Beira Baixa, que futuro?", os autores, (Marcelo \& al, 2003), referem que "os saberes e os sabores inerentes a tais produtos traduzem tecnologias produtivas em que se cristalizou a alma inventiva de sucessivas gerações e correspondem a especializações naturais que compõem o património produtivo $e$ gastronómico rural. Dão como exemplos, os "vinhos, os queijos, o azeite, o pão, o mel, os enchidos e a doçaria, que constituem todo um artesanato produtivo da maior importância para a preservação da identidade cultural e para o desenvolvimento sustentado das comunidades rurais".

D’Avila (1983), defende que nos países em desenvolvimento, a minimização da problemática do desemprego poderá passar, a curto prazo, pela aposta nas atividades de cariz artesanal. Isto por se tratar de uma área que não requer investimentos avultados, sendo, portanto, acessível a uma grande maioria da população. Para além desta vantagem economicista, refere que "o processo de produção artesanal reside ainda no resgate de valores humanos - habilidades pessoais, subjetividade, criatividade, liberdade de produção, autonomia, beleza - em contraposição aos processos industriais - de mecanização e automação". Conseguir implementar uma dinâmica de iniciativa, inovação e diferenciação pode, portanto, ser a chave para ultrapassar as debilidades características destas regiões.

\section{IDEIA DE NEGÓCIO: O CASO DA ALPHAZEMA - QUINTA PEDAGÓGICA}

Segundo os dados do Turismo de Portugal, em 2015, o número de Estabelecimentos de turismo de habitação e de turismo no espaço rural em Portugal era de 1298, sendo que de agroturismo apenas 194, ainda assim, mais 75 do que em 2014, ano em que tinha aumentado apenas 9 face ao ano anterior. Pressupõe-se que este crescimento seja motivado pelo aumento da procura desta tipologia de estabelecimento pois, o mesmo Instituto, refere que é um "segmento crescente da procura turística... considerando que se tem verificado um aumento de praticantes de atividades de ar livre"

O que se propõe com esta ideia de negócio é, portanto, a criação de uma microempresa - A Alphazema - Quinta Pedagógica - em que o pressuposto é o lançamento no mercado de uma empresa de agroturismo a operar em três setores de atividade: Produção, Serviços e Comércio. 


\section{Quadro III}

Segmentos de Negócio da "Alphazema - Quinta Pedagógica"

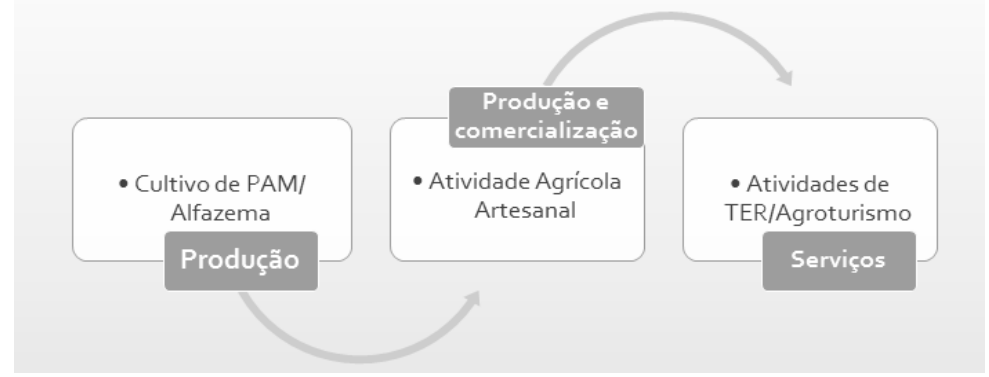

Fonte: Elaboração própria

O objeto principal da exploração será, como esquematizado anteriormente, a cultura de alfazema (espécie Lavandula angustifólia) e acessoriamente a exploração de atividades complementares e subsidiárias daquele objetivo, que se encontram identificadas no quadro em baixo por CAE e por percentagem de afetação de cada uma.

\section{Quadro IV}

Códigos CAE e percentagem de afetação

\begin{tabular}{|c|c|c|}
\hline CAE & Designação & $\%$ \\
\hline \multicolumn{3}{|c|}{ Códigos CAE caracterizadores das principais atividades da empresa } \\
\hline 01280 & $\begin{array}{l}\text { Cultura de especiarias, plantas aromáticas, medicinais e farmacêuticas (Venda } \\
\text { de produtos) }\end{array}$ & 55 \\
\hline 93293 & Organização de atividades de animação turística & 20 \\
\hline 47910 & Comércio a retalho pelo correio, telefone, televisão, leilões e via Internet, & 5 \\
\hline \multicolumn{3}{|c|}{$\begin{array}{l}\text { Códigos CAE secundários no âmbito das atividades de produção local identificadas no Anexo I } \\
\text { do diploma que aprova o Sistema da Indústria Responsável (SIR - Decreto-lei n.o 169/2012, de } \\
01 \text { de agosto) }\end{array}$} \\
\hline 11013 & Produção de licores e de outras bebidas destiladas & 5 \\
\hline 10830 & Indústria do café ou chá & 5 \\
\hline 10393 & Fabricação de doces, compotas, geleias e marmeladas & 5 \\
\hline 10720 & $\begin{array}{l}\text { Fabricação de bolachas, biscoitos, tostas e pastelaria de conservação - } \\
\text { Panificação }\end{array}$ & 5 \\
\hline
\end{tabular}

Fonte: Elaboração própria

Em termos de processo formal, e quanto à forma jurídica, a Alphazema - Quinta Pedagógica será uma Sociedade Unipessoal por Quotas, sendo apenas constituída por um único sócio, pessoa singular, que é o titular da totalidade do capital social, com sede em Alcains, onde se localiza a exploração. 
Do ponto de vista geográfico considera-se localizada num ponto estratégico, designadamente pela proximidade com a sede de distrito (10 $\mathrm{Kms}, 10$ minutos) e dista a cerca de 2,5 km da A23 (autoestrada da Beira Interior) que faz a ligação até à Guarda e à autoestrada do Norte A1 (em Torres Novas). Tem ainda a vantagem da ligação com o país ibérico vizinho ser relativamente próxima e facilitada, tendo em conta as boas redes viárias existentes.

Figura 1

Localização geográfica da empresa

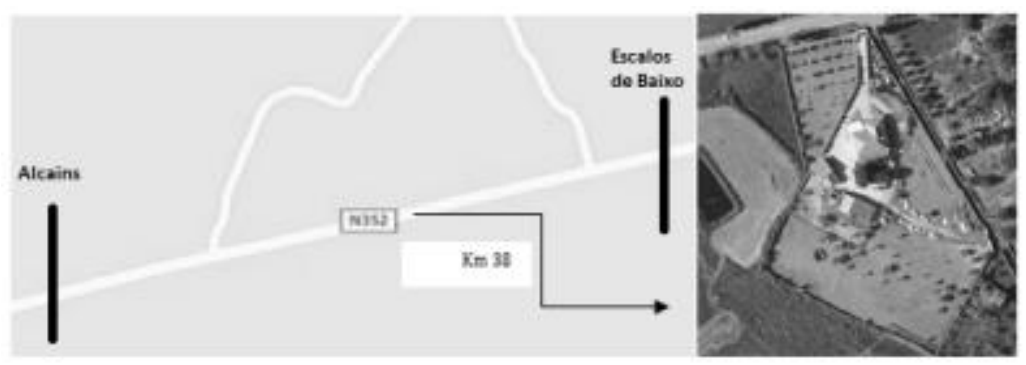

Fonte: Elaboração própria adaptada de www.bing.com

As potencialidades do espaço são, igualmente, outro fator considerado na medida em que se trata de uma exploração com cerca de $10.500 \mathrm{~m} 2$, plana, com solo adequado ao cultivo da planta, ou seja, grande exposição solar e pouca humidade, possui infraestruturas facilmente adequáveis, ao plano funcional que se desenhou para a empresa, possibilitando a operacionalidade e articulação dos espaços que constituem quer os edificados, quer o espaço exterior.

Como referido, o projeto em estudo prognostica algumas nuances diferenciadoras, quer ao nível dos processos, quer do processo produtivo. No respeitante ao processo core - produção de alfazema - destaca-se o facto desta ideia de negócio privilegiar a monocultura que se considera mais benéfica e rentável, na medida que permite uma maior especialização, menos mão-de-obra, pouca variedade de maquinaria e equipamentos e processo de distribuição facilitado. O processamento escolhido é a secagem efetuada artesanalmente e sem recurso a quaisquer produtos químicos, mantendo, assim, a autenticidade da planta, destinando-se maioritariamente à exportação através de uma parceria de distribuição com um produtor já instalado. Sendo a produção de flor de alfazema uma atividade sazonal, cuja época da colheita da flor será o ponto alto em termos de dinâmica desta vertente, coincidente com o período alto da 
realização de eventos ao ar livre, pretende-se assumir uma estratégia de maximização de recursos, designadamente a rentabilização da estrutura física, em particular dos espaços fechados, que serão utilizados para outro tipo de atividades, como preparação de produtos a partir das matériasprimas existentes na quinta, dinamização de workshops, ateliers, etc.

A existência de outros segmentos complementares é, por si só, um fator estratégico, na medida em que permite a diversificação do mercado e obter maior rentabilidade. Destaca-se o facto da comercialização de produtos fabricados de forma totalmente artesanal ser efetuada através de diversos canais de distribuição em função do produto e do correspondente cliente de destino, com foco no cliente individual e no tecido empresarial, podendo a venda ser efetuada no local, com recurso a uma loja instalada no empreendimento, on-line, em feiras tradicionais e lojas da especialidade.

Quanto à prestação de serviços, o foco é a realização de eventos de animação educativa em contexto agrícola, permitindo o acompanhamento das atividades e de eventos previamente planeados e adequados a púbicos concretos numa ótica de educação não formal que proporcione experiências agroambientais, seja em forma de visitas, workshops, ateliers, formação, festas e outros eventos à medida . O mercado alvo inicial é a comunidade escolar e as famílias com filhos da região, pretendendo-se o alargamento ao mercado nacional a partir do segundo ano de atividade, altura em que a beleza da plantação atingirá o seu auge e com a estrutura em pleno funcionamento.

É, portanto, nesta conjugação de serviços e produtos, que se pretende a criação de valor associada a uma rede de fornecedores e parcerias que partilhem interesses e estratégias comuns ou complementares e que permitam alianças, quer na entrada no mercado, quer na sustentabilidade a médio e longo prazo. Na fileira das PAM este pressuposto ganha ainda maior importância, pois sendo um mercado relativamente recente e em fase de expansão, a maior parte da produção é escoada por grupos de produtores já instalados, que têm a capacidade logística, conhecem o mercado e procuram, também eles, outros produtores que os forneçam e lhes permitam dar resposta às solicitações, essencialmente, provenientes do estrangeiro pois aquela visa, quase exclusivamente, o mercado de exportação.

Os elementos diferenciadores que se quer introduzir visam conquistar a diferença e a preferência sobre os demais operadores no mercado. Apesar de, a nível nacional, apenas três Quintas Pedagógicas operarem com o mesmo conjunto de serviços e a nível distrital, apenas uma, há que considerar a concorrência cada vez mais agressiva de diversas marcas no mercado que "trabalham" cada área de negócio isoladamente. Para tanto, a 
variável preço é determinante do ponto de vista da sustentabilidade económico-financeira da Alphazema - Quinta Pedagógica, pelo que se pretende que a estrutura de preços seja, a cada momento, definida em função dos aspetos que, efetivamente, beneficiem o cliente, tentando ajustá-los à média praticada pelos concorrentes, e recorrendo a políticas atrativas de descontos e fidelização.

Para a concretização da sua missão e objetivos, e dadas as pluriatividades da Alphazema - Quinta Pedagógica, o sucesso desta depende muito dos seus recursos humanos e das competências polivalentes destes, pese embora se trate de uma microempresa com cariz marcadamente familiar. Na fase inicial de instalação, será a promotora, auxiliada por familiares diretos, a realizar a maior parte do trabalho de gestão administrativa e sobre quem recairá a responsabilidade de tomar decisões, prevendo-se a contratação de 4 colaboradores, 1 Técnico de agricultura biológica, 1 Animador sociocultural, 1 Auxiliar e 1 Estagiário, sendo que os dois primeiros apenas a tempo parcial.

O lançamento no mercado da marca é um ponto crucial pois tratando-se do meio mais adequado para identificar a empresa e a forma, por excelência, de a distinguir das demais, é imperioso que seja pensada de forma cuidada. Assim, a começar pela escolha do design do logotipo, foi criada uma imagem que facilmente identifica o setor de atividade considerando alguns pontos como a cor, a planta, a forma de escrita, conciliando-os num design que fosse agradável à vista e que remetesse para a origem.

Figura 2

Imagem da empresa

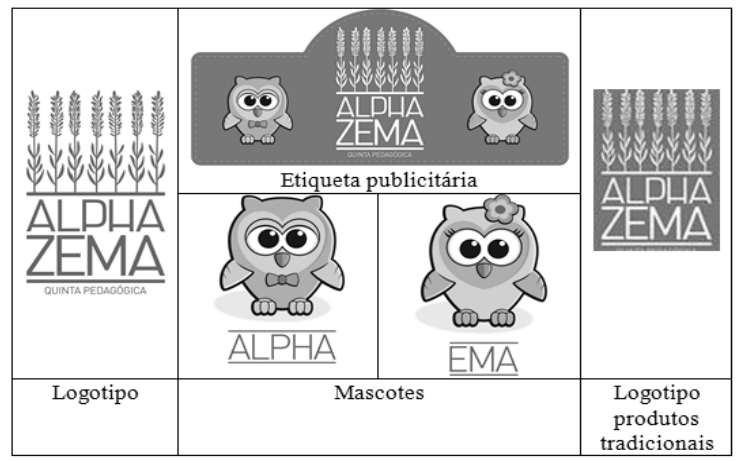

Fonte: Elaboração própria

Tendo em consideração que o logotipo nos remete, principalmente, para o setor da produção, no caso da Lavanda, vulgo alfazema, e 
considerando que a vertente pedagógica e de serviços é, também, um dos processos chave da empresa, com especial enfoque no público infantojuvenil, foram concebidas duas mascotes que pudessem atrair estes grupos etários e cujo design teve subjacente ideias como o facto de ser um animal, e, portanto, remetendo para a importância da preservação ambiental, no caso corujas, símbolo de sabedoria e uma dupla, valorizando o trabalho em equipa.

A par de todos estes fatores, o fenómeno da globalização empresarial implica que se tenha ainda em consideração o facto da imagem da empresa facilmente identificar o setor de atuação, independentemente da língua. É também neste contexto de globalização e de diversificação da oferta de produtos e serviços, que chegam ao consumidor a preços cada vez mais baixos e com níveis de qualidade, que as empresas, particularmente as de reduzida dimensão e que atuam em mercados locais, devem direcionar as tomadas de decisão com base em estudos que permitam perceber se, do ponto de vista económico, a mesma apresenta rentabilidade e é sustentável, assim como identificar os fatores críticos de sucesso de negócio.

Assim, o Plano económico-financeiro da Alphazema - Quinta Pedagógica está sistematizado nos mapas infra com o dos investimentos a abranger os três primeiros anos e os restantes a reportarem-se ao período de 2018 a 2023 na medida em que o início de atividade está previsto para 2018.

\section{Quadro V}

Investimento a 3 anos

\begin{tabular}{|c|c|c|c|c|c|c|}
\hline \multirow[t]{2}{*}{ Valores $(€)$} & \multicolumn{2}{|c|}{2018} & \multicolumn{2}{|c|}{2019} & \multicolumn{2}{|c|}{2020} \\
\hline & s/lva & c/iva & s/lva & c/iva & s/Iva & c/iva \\
\hline ATIVO INTANGÍVEL & $7.593,94$ & $9.340,55$ & $1.340,00$ & $1.648,20$ & $2.200,00$ & $2.706,00$ \\
\hline \multicolumn{7}{|l|}{ ATIVO FIXO TANGÍVEL } \\
\hline Equipamento básico & $5.404,06$ & $6.646,99$ & 865 & 1.064 & 1.212 & 1.491 \\
\hline Equipamentos de Transporte & 0,00 & 0,00 & 9.800 & 12.054 & 0,00 & 0,00 \\
\hline Equipamento administrativo & 970,46 & $1.193,66$ & 0,00 & 0,00 & 0,00 & 0,00 \\
\hline Outros Ativos Fixos Tangiveis & $36.406,25$ & $44.779,69$ & $4.636,25$ & $5.702,59$ & $20.000,00$ & $24.600,00$ \\
\hline TOTAL ATIVO FIXO TANGÍVEL & $42.720,77$ & $52.620,35$ & $15.301,42$ & $18.820,75$ & $21.212,42$ & $26.091,28$ \\
\hline TOTAL: & $50.374,71$ & $61.960,89$ & $16.641,42$ & $20.468,95$ & $23.412,42$ & $28.797,28$ \\
\hline
\end{tabular}

Fonte: Elaboração própria, adaptado do website www.iapmei.pt

O Plano de Investimentos foi programado para 3 anos, sendo que o investimento inicial rondará os $62.000 €$ no primeiro ano e cerca de $50.000 €$ divididos pelos 2 anos seguintes. A maior fatia do investimento respeita à reabilitação das infraestruturas e à aquisição de um veículo comercial. O financiamento terá a sua origem em capitais próprios 
(15.000€), empréstimo bancário (100.000€), fundos comunitários (51.235€) e fluxos operacionais. Na data da eventual concessão do apoio, no âmbito das medidas PDR2020 (Programa de Desenvolvimento Rural 2020), cujo valor se admite ser de cerca de 51.000€, tendo em conta o montante das despesas elegíveis, o referido subsídio serviria, em parte, para iniciar, em 2019, a amortização do empréstimo referido.

\section{Quadro VI}

Mapa de demonstração de resultados

\begin{tabular}{lrrrrrr}
\hline & \multicolumn{1}{c}{2018} & \multicolumn{1}{c}{2019} & \multicolumn{1}{c}{2020} & \multicolumn{1}{c}{2021} & \multicolumn{1}{c}{2022} & \multicolumn{1}{l}{2023} \\
\hline Vendas e serviços prestados & 37.939 & 46.925 & 64.852 & 105.365 & 143.813 & 190.937 \\
\hline Subsídios à Exploração & 30.741 & 8.709 & 11.785 & & & \\
\hline CMVIIC & 7.294 & 8.992 & 12.155 & 19.193 & 26.514 & 36.908 \\
\hline Fornecimento e serviços externos & 21.300 & 21.726 & 22.161 & 22.604 & 23.056 & 23.517 \\
\hline Gastos com o pessoal & 26.208 & 34.609 & 50.776 & 51.844 & 52.940 & 54.063 \\
\hline Imparidade de dividas a receber (perdas/reversões) & 862 & 1.058 & 1.444 & 2.317 & 3.148 & 4.166 \\
\hline EBITDA (Resultado antes de depreciações, gastos de & 13.015 & -10.750 & -9.898 & 9.408 & 38.156 & 72.284 \\
financiamento e impostos) & 7.031 & 10.026 & 12.078 & 9.612 & 9.369 & 9.072 \\
\hline Gastos/reversões de depreciação e amortização & 5.984 & -20.777 & -21.976 & -204 & 28.787 & 63.211 \\
\hline EBIT (Resultado Operacional) & 2.510 & 2.510 & 2.259 & 2.008 & 1.757 & 1.506 \\
\hline Juros e gastos similares suportados & 3.474 & -23.287 & -24.235 & -2.212 & 27.030 & 61.705 \\
\hline RESULTADO ANTES DE IMPOSTOS & 2.745 & -23.287 & -24.235 & -2.212 & 27.030 & 53.515 \\
\hline RESULTADO LIQUIDO DO PERIODO & & & & & & \\
\hline
\end{tabular}

Fonte: Elaboração própria, adaptado do website www.iapmei.pt

Pelo Mapa de Demonstração de Resultados verificamos que os Resultados Operacionais são satisfatórios, originando indicadores de rentabilidade muito interessantes para a área de negócio. Ou seja, o EBIT atinge valores positivos a partir do $4 .^{\circ}$ ano de atividade o que, tendo em conta o investimento e a dependência de capitais alheios, não é um resultado despiciendo, chegando em 2023 aos 63.211€ prevendo-se, nesse ano, um Resultado Líquido de 53.515€.

Os resultados positivos verificados no ano de implementação da empresa parecem ser contraditórios com os três anos seguintes, de resultados negativos, mas tal deve-se ao saldo de tesouraria acumulado decorrente das fontes de financiamento. A evolução positiva, em especial nos últimos 2 anos, decorre da evolução da produção principal da atividade da empresa (a alfazema), que atingirá o auge em 2021. 
Quadro VII

Mapa do balanço previsional

\begin{tabular}{|c|c|c|c|c|c|c|}
\hline & 2018 & 2019 & 2020 & 2021 & 2022 & 2023 \\
\hline \multicolumn{7}{|l|}{ ACTIV0 } \\
\hline Ativo Não Corrente & 41.725 & 47.000 & 55.135 & 45.523 & 36.154 & 27.082 \\
\hline Ativo corrente & 131.531 & 92.791 & 51.697 & 50.519 & 78.295 & 140.846 \\
\hline TOTAL ACTIVO & 173.257 & 139.791 & 106.832 & 96.042 & 114.449 & 167.928 \\
\hline TOTAL DO CAPITAL PROPRIO & 68.980 & 45.693 & 21.458 & 19.246 & 46.276 & 99.791 \\
\hline \multicolumn{7}{|l|}{ PASSIVO } \\
\hline Passivo não corrente & 100.000 & 90.000 & 80.000 & 70.000 & 60.000 & 50.000 \\
\hline Financiamentos obtidos & 100.000 & 90.000 & 80.000 & 70.000 & 60.000 & 50.000 \\
\hline Passivo corrente & 4.277 & 4.098 & 5.374 & 6.796 & 8.173 & 18.137 \\
\hline Fornecedores & 2.576 & 2.765 & 3.084 & 3.746 & 4.433 & 5.393 \\
\hline Estado e Outros Entes Públicos & 1.701 & 1.333 & 2.290 & 3.050 & 3.739 & 12.743 \\
\hline TOTAL PASSIVO & 104.277 & 94.098 & 85.374 & 76.796 & 68.173 & 68.137 \\
\hline TOTAL PASSIVO + CAPITAIS PROPRIOS & 173.257 & 139.791 & 106.832 & 96.042 & 114.449 & 167.928 \\
\hline
\end{tabular}

Fonte: Elaboração própria, adaptado do website www.iapmei.pt

Pelo Balanço previsional, verifica-se que em todos os anos o valor do Ativo é superior ao Passivo, ou seja, o Capital Próprio (a estimativa contabilística do valor do património) é positivo e, portanto, os bens disponíveis na empresa são suficientes para cobrir as dívidas, não obstante os resultados líquidos serem negativos de 2019 a 2021, em consequência, principalmente, da amortização do empréstimo bancário.

Conclui-se que o balanço "abona" a favor da sustentabilidade da empresa podendo dizer-se que o projeto apresenta viabilidade económica e financeira. Tendo em consideração que os dados são previsionais e sabendo que ao longo da vida de qualquer empresa surgem, frequentemente, situações imprevistas, devemos estar conscientes da possibilidade de existirem diferenças entre os resultados perspetivados e os resultados reais, quer estejam subjacentes cenários positivos ou negativos.

\section{CONCLUSÃO}

A globalização e o apelidado "fim dos territórios", remetem-nos para a ideia de que não existem territórios, mas sim um território global. Não obstante, verificamos que tal acarretou ainda mais desigualdades entre territórios. Parecendo duas ideias antagónicas, permitimo-nos concluir que, na realidade, pode ser nas desigualdades que se pode conquistar uma dimensão endogénica, já que a globalização permite dar a conhecer ao exterior as especificidades de cada região e tirar partido destas. Esta abordagem, cada vez mais valorizada, assume para os meios rurais uma janela de oportunidade na ótica do aproveitamento dos recursos (naturais, humanos, culturais, ambientais, patrimoniais, etc.) para o desenvolvimento de atividades económicas tradicionais numa perspetiva de inovação. 
COVAS (2007) defende mesmo que a ruralidade pode aparecer como uma $2^{\mathrm{a}}$ modernidade e que deve ser vista "como um território pleno de oportunidades de vida, de negócios, de trabalho, de educação e de cultura associado a atividades de lazer, turismo e artes e, ainda, como um espaço de promoção de saúde". Percebe-se, portanto, que não obstante os proveitos das empresas de cariz individual, familiar ou microempresas, que se dedicam a este setor do turismo, não terem muita representatividade no que à competitividade nacional diz respeito, as mesmas não devem ser desvalorizadas, pois assumem um papel preponderante na criação do próprio emprego, de outros postos de trabalho e na dinâmica de zonas marcadamente rurais e desertificadas.

\section{FONTES E BIBLIOGRAFIA}

AICEP - Agência para o Investimento e Comércio Externo de Portual Estatísticas. (s.d.). Consultado em 18 de dezembro de 2016, de http://www.portugalglobal.pt/PT/Paginas/Index.aspx

Banco de Portugal. Boletim Económico - dezembro de 2016. www.bportugal.pt

Bernat, H. (1996). Los nuevos consumidores, o las nuevas relaciones entre campo y ciudad a través de los productos de la tierra. Agricultura e Sociedad n. ${ }^{\circ} 80-81$.

Covas, \& D., M. (2007). O Desenvolvimento Rural. Consultado em 28 de 12 de 2016, de Universidade de Évora:

http://www.ela.uevora.pt/download/ELA_desenvolvimento_rural_04.pdf

Cunha, A., Ribeiro, J., \& Roque, O. (2009). Plantas aromáticas em Portugal - caracterização e utilizações. Lisboa: Fundação Calouste Gulbenkien.

D’Avila, J. S. (1983). O artesão tradicional e seu papel na sociedade contemporânea. Rio de Janeiro: Funarte.

De La Torre, O. (1992). El turismo, fenomeno social. Cidade do México: Fondo de Cultura Económico.

Decreto-Lei no 39/2008, de 07 de março. Diário da República n. ${ }^{\circ}$ 48/2008, Série I - Aprova o regime jurídico da instalação, exploração e funcionamento dos empreendimentos turísticos. Alterado pelo DecretoLei $\mathrm{n}^{\circ}$ 228/2009, de 14 de Setembro, que o republica.

Decreto-Lei $\mathrm{n}^{\circ}$ 41/2001, de 9 de fevereiro. Diário da República $n^{\circ}$ 34/2001, Série I-A - Aprova o estatuto do artesão e da unidade produtiva artesanal e define o respetivo processo de acreditação. 
Decreto-Lei $\mathrm{n}^{\circ}$ 251/84, de 25 de julho. Diário da República n. ${ }^{\circ} 171$ Define o regime de inserção do turismo de habitação na oferta turística portuguesa.

Decreto-Lei n. ${ }^{\circ}$ 256/86, de 27 de agosto. Diário da República $n^{\circ}$ 196/1986, Série I de 1986-08-27 - Estabelece normas relativas ao desenvolvimento das várias formas de turismo no espaço rural, revestindo a forma de «turismo de habitação», «turismo rural» ou «agro-turismo».

DGADR - Direção Geral de Agricultura e Desenvolvimento Rural. (s.d.). Consultado em 15 de outubro de 2016, de www.dgadr.mamaot.pt: http://www.dgadr.mamaot.pt/diversificacao/turismo-rural

Direção Geral da Saúde. Programa Nacional de Alimentação Saudável. (s.d.).

http://www.alimentacaosaudavel.dgs.pt/activeapp/wpcontent/files_mf/1 446660770Ervasarom\%C3\%A1ticasUmestrat\%C3\%A9giaparaaredu\% C3\%A7\% C3\%A3odosalnaalimenta\%C3\% A7\%C3\%A3odosPortuguese s.pdf

Eusébio, C. K. (2013). Tourism and sustainable development of rural destinations: A stakeholder's view. Proceedings of the International Conference on Rural Tourism . Aveiro: The ORTE Conference.

Figueiredo, A., Barroso, J., \& Pedro, L. (2007). Potencialidades $e$ aplicações das plantas aromáticas e medicinais. Lisboa: Faculdade de Ciências da Universidade de Lisboa - Centro de Biotecnologia Vegetal. GPP - Gabinete de Planeamento, Políticas e Administração Geral. (10 de 2013). As Plantas Aromáticas Medicinais e Condimentares. (M. d. Mar, Ed.) Obtido de http://www.gpp.pt/index.php/\#.

INE-Instituto Nacional de Estatística. (2016). Consultado em 23 de setembro de 2016:

$\mathrm{https} / / /$ www.ine.pt/xportal/xmain?xpid=INE\&xpgid=ine_publicacoes\& PUBLICACOESpub_boui $=233015003 \&$ PUBLICACOESmodo $=2 \&$ xla $\mathrm{ng}=\mathrm{pt}$

INE-Instituto Nacional de Estatística. (2016). Estatísticas de Turismo 2015. Estatísticas oficiais. Edição 2016. ISBN 978-989-25-0358-5

Jardim Botânico da Universidade de Trás os Montes e Alto Douro (2016). Flora Digital. Consultado em 03 de novembro de 2016, de Utad Jardim Botânico: http://jb.utad.pt/especie/lavandula_angustifolia

Jesus, L., \& Kastenholz, E. (2008). A oferta do turismo no espaço rural. Estdo do caso da Região - Dão-Lafões. Atas do 7. ${ }^{\circ}$ Colóquio Ibérico de Estudos Rurais. Coimbra.

Kastenholz, E. (2014). Cocriação de experiências turísticas sustentáveis. Aveiro: Universidade de Aveiro. 
Kneafsey, M. (1998). Tourism and place identity. A case-study in rural Ireland. Ireland: Irish Geography.

Lei n. ${ }^{\circ}$ 8/2016, de 1 de abril. (s.d.). Diário da República n. ${ }^{\circ}$ 64/2016, Série $I$ - Procede à décima alteração ao Código do Trabalho, aprovado pela Lei n. $.^{\circ} 7 / 2009$, de 12 de fevereiro

Mancebo, D. (2002). Globalização, cultura e subjetividade: discussão a partir dos meio de comunicação de massa. Instituto de Psicologia, Universidade de Brasília. Rio de Janeiro, Brasil: Universidade de Brasília.

Marcelo, L., Santos, D., Coelho, A., Carvalho, G., \& Alves, R. (2003). Beira Baixa, que futuro? Castelo Branco: Governo Civil de Castelo Branco.

Memorando de Entendimento sobre as Condicionalidades de Política Económica. (2011, maio 17). Consultado em 21 de agosto de 2016, de http://www.portugal.gov.pt/media/371372/mou_pt_20110517.pdf

Mesquita, S. (2004). Breve história dos hortos de aromáticas e medicinais em Portugal. Lisboa: Apenas Livros Lda.

Miranda, M. (2009). Áreas de Preservação Permanente e Reserva Legal. Curitiba: Instituto Agronômico do Paraná - IAPAR-Unidade Regional de Pesquisa Leste.

Moreira, J. R. (2003). Cultura, Política e o Mundo Rural na contemporaneidade. Estudos Sociedade e Agricultura.

OMT - Organização Mundial do Turismo. (s.d.). Plano Estratégico Nacional do Turismo: revisão e objetivos 2013-2015. Consultado em 15 de junho de 2016:

http://www.turismodeportugal.pt/Portugu\%C3\%AAs/turismodeportuga 1/publicacoes/Pages/PublicacoeseRelatorios.aspx

Pardal, S. (2002). Planeamento do Espaço Rústico. Lisboa: Associação Nacional dos Municipios Portugueses e Universidade Técnica de Lisboa, ADESA, CESUR. Obtido de Associação Nacional dos Municipios Portugueses.

Partidário, M. (2003). Turismo em espaços rurais e naturais: uma oportunidade sustentável. Coimbra: Instituto Politécnico de Coimbra.

PORDATA. (26 de 02 de 2016). Balança de Viagens e Turismo. Obtido em 11 de 3 de 2016, de Pordata - Portal de Dados Comtemporâneo: http://www.pordata.pt/Tema/Portugal/Turismo-82

Turismo do Centro. Estatistica 2016. Consultado em 06 de setembro de 2016, de Turismo Centro Portugal:

http://www.turismodocentro.pt/profissional/pt/estatistica.123/estatistica _2016.140/estatistica_2016.a108.html 
PRODER - Programa de Desenvolvimento Rural. (2014-2020). Consultado em 14 de março de 2016: http://www.proder.pt/

Santos, N. P. dos (2011). Lazer tempo livre e novos consumos. Hernâni Veloso Neto e Sandra Lima Coelho (Org.) - Novas dimensões do consumo na sociedade contemporânea, Porto: IS-FLUP, pp. 84-97.

Silva, A., Lima, F., \& Chamusca, P. (2010). Estratégias de eficiência colectiva em territórios de baixa densidade: reflexões a propósito do Minho-Lima e do Tâmega. XII Colóquio Ibérico de Geografia. Faculdade de Letras da Universidade do Porto.

Souza, G. M. (2012). Lavanda, Alfazema ou Nardo? Consultado em 15 de novembro de 2016, de http://magiadailha.blogspot.pt/2012/08/lavandaalfazema-ou-nardo.html

Tourism, Hospitality \& Leisure. (2016). Obtido:

http://www.worx.pt/pt/servicos/tourism-hospitality-leisure

Turismo de Portugal, I.P. (2016). Turismo em números 2015.

Turismo de Portugal, I.P. (2015). Turismo em números 2014.

Instituto Nacional de Investigação Agrária e Veterinária. Consultado em 7 de dezembro de 2016, de Instituto Nacional de Investigação Agrária e Veterinária: http://www.iniav.pt

Vida Imobiliária - Turistas Portugueses preferem Alojamento Local. (2016). Consultado em 23 de setembro de 2016:

http://www.vidaimobiliaria.com/noticia/turistas-portugueses-preferemalojamento-local

Vieira, A. L. (2010). Relationship Marketing and the Philosophy of Science: A Tribal Journey Through Relationship Quality. Journal of Relationship Marketing.

Viklund, A. (2010). Historia da erva medicinal. Fitoenergético: A saúde em suas mãos.

Web Summit Lisbon. (s.d.). Consultado em 25 de novembro de 2016, de http://www.websummitlisbon.pt/homepage/

World Travel Awards Winners. (2016). Consultado em 10 de setembro de 2016: https://www.worldtravelawards.com/winners/2016

Zuzarte, M; Vale-Silva, L; Goncalves, MJ; Cavaleiro, C; Vaz, S; Canhoto, J. (2012) Antifungal activity of phenolic-rich Lavandula multifida $L$. essential oil . European Journal of Clinical Microbiology \& Infectious Diseases. Volume 31, Issue 7, pp 1359-1366.

https://link.springer.com/article/10.1007\%2Fs10096-011-1450-4

WTTC - World Travel \& Tourism Council . (2015). Consultado em 13 de junho de 2016: http://c/summits/the-global-summit-2015/ 